\title{
Student Research Work and Modeled Situations in Order to Bridge the Gap between Basic Science Concepts and Those from Preventive and Clinical Practice. Meaningful Learning and Informed beneficience
}

\author{
Elio A. Prieto González \\ Center for Higher Studies of Health and Human Sciences, Universidad Abierta Interamericana, Buenos Aires, \\ Argentina \\ Email: Elio.Prietto@vaneduc.edu.ar
}

Received 16 December 2015; accepted 16 May 2016; published 19 May 2016

Copyright (C) 2016 by author and Scientific Research Publishing Inc.

This work is licensed under the Creative Commons Attribution International License (CC BY). http://creativecommons.org/licenses/by/4.0/

c) (i) Open Access

\begin{abstract}
Meaningful learning of basic science concepts is a difficult goal to reach among students from different health related university careers. We present an integrative approach based on different educational strategies like problem based, and situated learning as well as the use of models and organizers. Three cases from Medicine, Nursing and Nutrition show the difficulties in the comprehension and integration of basic and applied knowledge as well as the educational approaches adopted and the evolution of students. There is a discussion on the ethical relevance of deep basic and applied knowledge in the right solution of problems posed in class that attempt to model real life scenarios. There is a term introduced in this paper: informed beneficence. This concept expresses the assumption that the professional fulfillment of the ethical principle of beneficence is linked to knowledge and skills to propose appropriate solutions to individual or collective health problems.
\end{abstract}

Keywords

Ethics, Meaningful Learning, Basic Science, Biology Education

How to cite this paper: González, E. A. P. (2016). Student Research Work and Modeled Situations in Order to Bridge the Gap between Basic Science Concepts and Those from Preventive and Clinical Practice. Meaningful Learning and Informed beneficience. Creative Education, 7, 952-962. http://dx.doi.org/10.4236/ce.2016.77099 


\section{Introduction}

In my experience as a teacher in Biology and Investigative Methodology in Medicine, Nutrition and Nursing, I have found a similar problem in students of different careers: a difficulty to integrate in a coherent view, the knowledge related to biochemical and physiological mechanisms, those concepts that implicate a great deal of abstract thought like investigative methodology or biostatistics and those that are more practical and instrumental.

The integrative view linking basic science contents and clinical or epidemiological issues is often hampered by the reluctance to accept the basic contents as an obliged stage in the learning process in university careers related to Health Sciences. This is by no means a discovery, but the fact that there are no relevant differences in the prevalence of such a controversy between students of different careers is against the odds (Hackett et al., 1994; Ceballos, 2007).

It is a common assumption that students of a career with greater theoretical difficulties or a higher codified language would be in a better position to get a whole integrative picture of those concepts that connect the basic sciences and those directly related to health practice (Domínguez Gutiérrez, 2013). Conversely, I have found that differences in integrative capacities mainly aroused on individual basis among the students in any of those careers i.e. Medicine or Nursing, being the more influential factors: motivation, the previous readings, not related to the biological or epistemological contents but to general culture and their home cultural environment among others (Kosgeroglu, 2009; Bjorg et al., 2013).

Another issue that must be considered and is tightly related to motivation is the axiological factor expressed in the compromise toward others assumed by the student that is related to the importance given to what I have called "informed beneficence".

In the first lecture of the academic year, I usually emphasize the need of a proper knowledge to fulfill the second ethical commandment for acting in a beneficial way for the people. The natural consequence of the ethics substrate that is implicit in learning, leads to the conclusion that the first medical commandment "primum non nocere" does always need a good deal of knowledge to avoid damage to the potential subjects of the clinical or preventive practice.

This imprescindible need of scientific knowledge to do the good for the peoples' health is what I have called "informed beneficence" and represents one of the educational axes in the attempts to develop a moral motivation in students that could lead to improvements in the learning process. One of such improvements could be a greater proneness toward the integration between the "harder" contents from Biochemistry, Cell Biology and Immunology and more practical items like the link between, for instance, the preventive measures against obesity and the comprehension of cytoquines involvement in the insulin resistance during development of type 2 diabetes.

In other words, our viewpoint implies that it isn't possible to understand the meaning of clinical data, the basis of therapeutical procedures and the logical of preventive medicine or nutrition without basic knowledge. That assumption is being the centre of a controversy between those that consider that basic contents have a limited value in most of the cases during professional practice (Norman, 2000; Lazic et al., 2006; Muller \& Case, 2010) and those that support that basic knowledge is the ground, not only for a right and significant learning in every field and support for a professional practice (Feudmer \& Christakis, 1994; Spencer et al., 2008; Kember, 2009; Pangaro, 2010; Armstrong, 2012). From our experiences, it arises the assumption that a deep and meaningful learning rooted in the ethics of responsibility is a good way to allow students and future professionals to fulfill the bioethical principle of beneficence.

\section{What Is Obvious and When It Isn't}

Literature regarding current proposals for Biology Education remarks some core concepts that must be considered in Biology courses: 1) evolution; 2) structure and function; 3) information flow, exchange and storage; 4) Pathways and transformation of energy and matter, and 5) systems. In our experience this five foundational elements are instrumental to develop a knowledge frame in Biological related careers. As a complement to those core concepts there are also a group of competencies and abilities that have been considered mandatory for undergraduate studies, for instance, in USA (AAAS, 2011). The tasks that must be reached in Biology Education include: ability to apply the process of science, from hypotheses to design of the proper test procedure; 2) ability to quantitative reasoning; 3) ability to develop modeling and simulation, ability to understand the interdisciplinary nature of science that allow to communicate and work together with other disciplines and the ability to 
discuss the relationship between science and society regarding bioethical issues (AAAS, 2011).

The development path of Biology education is signed by the explosive growth of information in Cellular and Molecular Biology, Genetics, Ecology and Computational Biology, but there is a need for bioethics as complement in the current contents of Biology, not only as an isolated topic, but primarily as a core component of those issues that are the background for those that are in the core of Health related careers.

The theoretical background that support the many ways that are explored to teach Biology contents as updated as could be possible, is extremely wide and have conduced to visions that are necessarily eclectic in its nature with differential emphasis according to authors that has been selected by scholars or educational programmers (Pellegrino, 1993; Burnard, 1999; Resnick, 2009; Acosta \& Garcia, 2012; Rowe et al., 2015).

It is apparently obvious that without basic knowledge there is not possibility to construct a frame for applied knowledge. Without this foundation, the health procedures would be done mechanically, resulting in maleficence more often. This assumption is recognized by the students but it is not automatically translated to a better predisposition to those basic matters, or in the adoption of study goals oriented to a deeper acquisition of that basic knowledge.

In my class, the emphasis has been settled upon designing tasks for individual and collective work linking basic concepts with professional demands. These activities are intended to attain a deeper learning in the context of a simulated situation that helps to highlight one aspect that I considered relevant to raise a greater motivation toward basic science as a stand point for beneficial professional practice. This aspects that is pivotal to understand what is the meaning and the need for a deeper learning is the ethical discussion about the consequences of miss judgment related to flaws in basic knowledge.

Ethics, Deontology and Bioethics curriculum in higher educational centers have been focused on issues spanning from the protection of scientific research subjects, the beginning and the end of life to the new challenges posed by new diagnostic/treatment procedures and the impact of DNA manipulation, cloning and transgenesis. However it is necessary to consider also Ethics in the hidden curriculum in the learning process of many disciplines when is incorporated to their academic body not as a separate course (Potter, 1988, Adams, 2011, Weyrich \& Harvill, 2013; Clarke, 2014).

Problem Based Learning (PBL) is one of the educational strategies more amenable to embody and develop an ethical side. PBL educational procedures are intended to recreate a real situation ("situated learning"; i.e. McLellan, 1996) while focusing on the development of student's abilities in recognize and establish connections between theory and practice. There is also a need to take in consideration the responsibility aroused from decisions adopted in the modeled situation. Is in that sense that the connection between the education based learning and ethics must be remarked because is a powerful tool in order to place the future professional in front of the consequences of bad choices adopted as a result of poor knowledge and limited analytical or practical skills (Gilbert \& Boulter., 1998; Giere, 1999; Schwarz et al., 2009; Magnani \& Nersessian, 2002; Fortus et al., 2005; Tarhan \& Ayyıldız, 2015).

In PBL there is an emphasis is on the reality of the scenarios, the ability to work collaboratively, fulfilling responsibilities and expression of ideas. The goal is to simulate triggering situations that force the students to solve situations (Kilroy, 2004). Education should promote the development of active learning to achieve "understanding and applicability and heuristic gain and the communicative relationship between knowing subject, around a knowable object" (Rodríguez et al., 2007; Felder \& Brent, 2009). When the problem proposed to students is analyzed, one of the dimensions that must be discussed is the consequences for the patient or communities if the proposed solutions are wrong. The ethics of care, the health's worker responsibility is addressed through a consequentialist approach (Veatch et al., 2009) and their experiences connecting PBL and ethics (Tysinger et al., 1997; Fasser et al., 2007).

The methods and procedures that I have adopted in order to apply the basic concepts from Cell Biology and Genetics to clinical and epidemiological scenarios, involves remarkably, the ethics issues not as a separate aspect but in a mixture with the scientific basic concepts. The procedures that we developed in order to reach that goal will be discussed here.

These procedures have been performed in class during the past three years and includes: 1) the involvement of students in bibliographic research about a problematic situation; 2) the identification and discussion of clinical cases, not only brought by us, but also by students; 3 ) the use of media resources; 4) the simulation of a real world event and 5) the analysis of the consequences of certain interpretation/diagnosis of that events and the ethical approach when the students, evaluate the results of the several courses of actions derived from that diag- 
nosis. The contribution of a poor theoretical basis to the distance between the right solution and those that are finally considered wrong are analyzed also under ethical grounds.

The theoretical assumption behind our practices is related to some aspects of PBL in combination with an expositive strategy using organizers. We consider that a strict PBL procedure sometimes doesn't achieve good results (Norman \& Schmidt, 2000; Keijsers et al., 2009). Our eclectic method is intended to avoid the pure memorization that is usually linked with basic science areas but the combination of mnemonic processes with reflection upon its connection with real world practice (Wilkerson \& Gijselaers, 1996; Wood, 2003).

We tried to develop activities that resembled, but inversely, the process of representation that is ontogenetic according to Brunner that includes: Enactive representation (action-based), Iconic representation (image-based), Symbolic representation (language-based) (Bruner, 1960). Our approach includes those steps that are considered for the development of PBL activities and are not limited to Education in Medicine but also for Nursing and Nutrition.

Nursing, Nutrition and Medicine students express different characteristics of the afore mentioned problematic. However, in spite of their different curriculums, students from these careers shows the same reluctance to address the multilevel approach to understood for example, etiology of diseases as diabetes or obesity, or the discussion and comprehension of the theories and hypotheses that underlie the adoption of screening procedures and the avoidance of certain behaviors, like eating a high fat caloric diet or smoking.

\section{How Do We Do}

In order to explain our experience in bridging gaps between basic concepts and practical skills in different careers, three cases will be discussed. In each case one student from a given career will be presented, and its evolution along their classmates during an academic year, as well as the responses to the educational procedures in the specific case and the near group.

In this study we put the look on several characteristics that influence upon the reluctance/acceptance to bridge basic and applied contents. Those were: age, genre, career, motivation, reading habits, critical thinking skills, invoked professional objectives, abilities to search information regarding the significance of those basic contents given in class and also the ability to recognize scenarios for preventive actions and to propose measures that should be based in the contents of basic sciences (Kosgeroglu, 2009; Yasushi et al., 2013, Azizi-Fini et al., 2015).

I use to signalize the main contents of the classes focusing on those basic topics that could be linked to situations in the practice. During the preparatory stage, when classes upon a particular unit are planned, the selection of advanced organizers is mandatory, but some of these organizers are related to ethics. Ethics of decision making that helps students to understand the linkage between their knowledge and skills and the consequences for health and welfare of individual subjects and populations.

\section{Study Cases}

\subsection{Case 1}

$\mathrm{JC}$, female, 26 years old studying in its first year of Medicine, is an active leader in the group with a tendency to explain openly its opinions that are supported by a good deal of general knowledge based in readings that exhibits a wide interest, from history and policy to theatre and scientific issues. JC expresses several times in class that in her opinion the study of cells characteristics or the property of substances that could be transported through the cell membrane was useless for a practitioner working in the real world in a hospital o clinic in its country. JC was interviewed about its cultural home environment and explained that she lives with her step father, a ballet professor and her mother, a high school teacher, being her father, whom she is in close contact, a theatre director. In her home there are often discussion about cultural and political issues and she have been used to argument and to express its opinion in a manner that is supported by quotations of authors from disciplines as History, Sociology or Political Sciences.

As soon as I knew about that home environment, I realized that there was a bias toward the humanistic viewpoint in detriment of the natural sciences, but surprisingly she was active in class, answering the more difficult questions while continuing with the critics on the pertinence of Cell Biology and Biochemistry to the future professional practice. 
I evaluated that in the case that JC could change her position in the class, her evident leadership, would act as a shortcut towards another student's better acceptance of the purpose of this hard matter that was previously considered in her own words as "time consuming, full of details and detached from the reality of a physician work".

I promoted the viewing of the film "A civil Action" based in the case of Worburn, a city contaminated with hexavalent chromium where a cluster of cancer among children surged. We discussed the film from the perspective of ethics and the responsibility of private and public toward environment and Public Health. Then, the problem to face was presented emphasizing the purpose of find a demonstration of what and how chromium can damage DNA resulting in cancer causing mutation.

After that discussion we returned to the classification of point or chromosomal mutation and the disarray of the informational control machinery in the cell. Then a practical word was assigned to JC and a team of four students. To find and expose the clinical manifestations of some leukemias in childhood, the epidemiology, life expectancy and treatment, This would be analyzed in two weeks, meanwhile, we continue studying, pointing to those steps that could be related to carcinogenicity.

JC and colleague's job was complemented by a research about cancer causing exposition, a work that was made by all the class grouped in teams of four. The objective was to identify that carcinogen, the source in the environment and the cancers that were related with.

When JC exposed their investigation with the help of a set of images, the group was shocked by the fact that those compounds regarded as carcinogens that surround us were capable of causing such harm.

Then my proposal was formulated as a first question: How to avoid DNA damage and mutation? The answer to that question was impossible without the knowledge of what is under the mutation, the change, the breakage of the equilibrium in DNA chemistry and information. More important was that the answer for that question was also the origin of several ones.

In the following months the entire class was involved often in discussion about other relationships between a molecular alteration as glucose or fat intake, and diabetes, or the danger of arsenic in water.

I cannot say that every student changes their attitude toward a signature, but there were good quantitative and qualitative results. JC expressed many times that those contents would be useful for the clinical practice but also for the prevention and chose a subject for its thesis "Behavior related to cancer development in a population from the capital city".

There was a jump from the terrain of movies like the already mentioned to the understanding of the importance of a knowledge that helped them not only to interpret what happened really beyond what the movie showed, and how it could be beneficial for their practice.

She expressed in an interview that her main objective was to work in a hospital, preferably in a big and complex one; she considers that its ability to gain the skills and knowledge that is needed for operating the complex devices that she will find there must be linked to the comprehension of the theoretical frame that surrounds the procedures developed in such a facility. JC finally understood that the relationship between beneficence and knowledge refers also to knowledge that is not related at a first sight with a practitioner activity.

In this case the change towards a favorable opinion on those basic subjects aroused not only from the impact of the narration that linked environmental exposures, and cancer, but also from the discussions over time she developed the project for her graduation thesis as a way to propose a way to solve that health s environmental problem. The remarkable fact was that JC reached the conviction that cancer prevention is part of medical attention and that only can be properly achieved if the basic facts of pollutants, mutation and malignant transformation are known by health professionals.

\subsection{Case 2}

This student is AL, a 26-year-old female without any reading habit, that comes from a home where her both parents are blue collar workers. Mother was also an inquisitive autodidact with several courses on subjects as Ikebana, redaction and reading. AL has a younger brother finishing High School in a public institute.

She had a good performance in all the matters that are related to Nurse's work but is reckless and reluctant to study Investigative Methodology, that consider as unnecessary to be a good nurse and highly abstract and hard to be elaborated in a coherent view. She also expressed that "research is for scientist not for nurses and less for students that are forced to study something that's alike philosophy". Her main objective was to work in geria- 
trics and learn about alternative medicine. AL is shy but communicative and her prevalent link in the classroom was with those students poorly motivated and scarcely participants.

As a procedure to close the gap between basic Cell Biology, research and practice, I decided to test the students' ability in the formulation of investigative questions related to disease prevention. These questions should be grounded in their previous biology knowledge.

Students were hardly able to make references to their knowledge of Biology and Physiopathology. It was necessary to develop an initial theoretical support to their questions. The first activity had has to be concluded in the span of two hours with access to the literature. AL developed her work with acceptable formal results; however she proposed a dissertation topic that was related to pseudo scientific practices such as Reiki.

That proposal was rejected after an open argumentation in class upon the lack of physiological basis for these "alternative treatments". Another reason for the negative was that the viewpoint adopted by AL was that of a critical acceptance of such quasi concepts as "hands energetic transference" in the Reiki practice. We analyzed in class that the study of alternative practices should be done from the theoretical background provided by the mainstream science that have been verified in facts and supported inside the accepted scientific paradigm.

Topics of alternative medicine in which there was a scientific explanation or at least a scientific approach to interpret and support the basis for those procedures or results were proposed, since that scientific background could explain and predict outcomes in modalities such ozone therapy or certain phytotherapy.

AL got good grades and was received as a nurse, but I couldn't overcome her aversion to the scientific theory that could support her hypothesis about the applicability of Reiki to nurse practice. In this case we tried to change the way the student approaches the scientific facts: the idea that the alternative medicine is more natural and does not require a detailed explanation based on the body of scientific knowledge, was rejected by us and was discussed openly in the classroom but pseudo scientism prejudices and preconceptions about how do good, prevailed. AL did not finish her thesis; her work was hampered by the impossibility to sustain the theoretical background that is lacking in the procedures she wished to study.

That thesis subject wasn't prohibited authoritatively; the un-acceptance was a consequence of the fact that she couldn't adopt a qualitative ethnical approach that embodied the criticism implicit in the study of those practices. We were unable to make she understand the fragrant contraposition of those practices with the biology knowledge. The gap in this case remained open ${ }^{1}$.

\subsection{Case 3}

Almost the totality of class in the second year of Nutrition Degree had rejected those topics related to Biochemistry and Cell Biology. The first class day I told to students that certain previous knowledge shall be mandatory in order to fulfill the requirements of the current course.

The topics that students in the second year have to review were: signal transduction, Cytokines and its cellular actions, Oxidative stress in obesity, the regulation of liver production of glucose and the glycolytic way. This knowledge that was necessary to understand the current themes was called "transversal topics". Those students that had have managed to study those issues in depth and to understand the main concepts, succeeded in reviewing the contents and began to integrate the previous knowledge with the processes that constituted the core of present themes. They were unfortunately few.

PER is a 22 years old male student that belonged to the group that rebelled against the need of "going backward to see those already approved stuff'. He wasn't able to perform a synthesis between that previous information, and the present demand. In spite of that, he could repeat with relative accuracy many of the previously mentioned subjects.

Lest say, I could identify two groups: those who recall and manage the previous information and were able to understand easily the new themes, and those who had "suddenly forgotten" the knowledge that have supposed to be acquired during the two previous year. The second group of fourteen students was also splitted in two: those who under my guidance and also the advice of their previous professor reached a deeper significance to that information, connecting the previous concepts with the new ones and those who couldn't make a synthesis; this comprise five from fourteen students. PER who remembered by heart the contents but couldn't integrate those with the present topic, belonged to the latter.

\footnotetext{
${ }^{1}$ Two years later she adopted a new thesis theme and concluded her degree, the controversy between her personal belief and scientific evidences was unsolved but her new thesis was related to instrumental practices in Nursing, where this issue wasn't relevant.
} 
PER is the second son of a couple composed by secondary school teacher and a housewife. During the high school years he was considered a good student because he had the ability to reproduce concepts by heart. He liked to read, especially novels and short stories, and also developed a taste for science, but based in poor quality publications where true scientific knowledge was interspersed with false concepts. As he is argumentative and considers stubbornness as a better quality over self criticism and skepticism, it was very difficult to reach a consensus about the need of precise knowledge when biological processes are studied. He was confused between the idea of mind freedom and the conceptual vagueness of terms like "biologically active" "molecular rearrangements" or "DNA influence". On the other hand the four remaining non successful students were effortless and poor motivated a situation that augmented as they recognized those biochemical and physiological contents as stressful and difficult.

We proposed a problem disaggregated in two questions: What is the effect of Body Mass Index in the cancer incidence in population in developed countries? How this relationship, if any can be explained? In this case the approach was to encourage the investigative activity through Internet. This search was conducted by groups of four students, following strict rules on the selection of websites and the answers that had to be obtained. The information had to be organized and delivered as practical home work. The time allowed to do this research was four weeks, during this period students were encouraged to discuss the topics treated in class under the perspective of the "transversal topics".

Afterward they had to make a Conceptual map, but with the use of arrows and legends to remark the processes. A special interest was given to the anatomical places where processes occurred. No bubble was allowed without the clear positioning in, for instance, the liver or the adipose tissue. When it was considered necessary, positioning was downgraded to cell and inside the cell, to specific organelles.

In such conceptual maps there were elements of thinking maps (Hyerle, 2008) with the intention of attaining a meta-cognitive task and the ability to transfer this process into reading, comprehension and a coherent explanation. In these experiences I wasn't attached strictly to those instruments, but that approach served, as a guide to draw conclusions about those aspects related with a higher success rate, when those students were evaluated. Finally, the integration of different processes at biochemical, histological physiological levels in schemes leaded in most of students to get a totalizing picture of a particular subject. The same process was scaled up to include all the contents in the matter, i.e. Metabolic Syndrome from obesity to diabetes, hypertension, dyslipidemia, and inflammation and prothrombotic state was deployed as a whole picture. Additionally when focusing subordinate phenomena like hypertension related to insulin resistance, inflammation and endothelial dysfunction were also depicted as inserted schemes.

The use of time lines in order to organize phenomena chronologically and the use of 2D and 3D models, developed by students, contributed to a more significant and lasting knowledge.

The process was completed with deductive and inductive explanations, going forward and backward along different complexity levels, it was done individually but also collectively in class, while explaining and writing the schematic maps and pictures on the board.

The result is the attaining of cognitive interconnections between the processes of vocabulary learning, spatial and chronologically, as well as meaning making. It was the case of PER that accepted to that preciseness was a need in explaining those process with a consequential change in its attitude toward basic science, an attitude that lead him to succeed.

Alternative to this approach, a case study and open discussion in class at the end of each subject was employed. Even those four students that were catalogued below the average improved their performance and evaluation results.

There is an exercise in which the students after having concluded the case analysis have to represent in a map the relevant aspects of that case, organized hierarchically. This one combined the generalization of abstract concepts and the simulation of a real case, with the ingredients of evaluation and decision making related to patients or community welfare. This process can only be developed through integrative application of the basic knowledge. Cause-effect reasoning is decisive in developing the analysis of the whole process, so as to be able to reach a coherent conclusion that should be represented graphically. Then, they should explain it to a student's audience.

The links between the information provided in the case report and the diagnosis or explanations given by students that succeed and those that didn't are both explained, but also, what would be the consequences in the case of incorrect analysis of the case. A close and prospective guidance and a balance between concepts and narration 
helped student to figure out what the reality would be in terms of responsibility and non maleficence to the others (Rognstad \& Aasland, 2007, Chamany et al., 2008; Labov \& Huddleston, 2008). When all the teams have been evaluated, there is a preliminary conclusion that is presented by the teacher. The final conclusion came after those participants expressed their criticism about the work done.

\section{Conclusion}

Human learning and of course the process of incorporating behavioral changes can lead to a shift in the meaning of the experience, according to the pedagogical approach of Ausubel (1960) as a source of significant learning theory. Our viewpoint is that in every class there is a need for motivation by using the own professor's experience to demonstrate the relevance of let's say, point mutation in a DNA repair gene and the way of life of a child with Xeroderma pigmentosum and its parents, forced to make a nocturnal life to avoid sunlight and hence skin cancer. Professors should act as social communicators as well as lecturers, but this communication must consider the ethics of the educational process as a way to be prepared as social compromised professionals.

The assertion that the educative bridge results from the professor profile regarding, emotional contention, mentorship, imagination, communication, and research activity, does not means that results automatically in promotion of deep learning in basic science with the proper connection to professional skills, on the contrary, the ability to do this job requires the identification of the goal and the development of educational vision that puts the accent in unifying the basic contents and their influence in the lives of those who we care of. It means an open discussion between teachers and students and a good deal of training (Enríquez Clavero et al., 2009; DeHaan, 2009; Balanay \& Roa, 2013). "The fundamental teaching problem is creating a situation, which originates from the contradictions between the experience of students and the problems they face in solving a cognitive task set. So, this situation leads to teaching problem when the unknown becomes the sought in the intellect of the learner. The teacher problem results in a search process, by solving tasks and problem question" (Guanche Martínez, 2005).

The approach we adopt incorporating meaningful learning is based on establishing cognitive connections between prior knowledge of students and new ones. In other words, we ignore the interventionist attitude focused only on the professor's knowledge and we get to know and to value the knowledge of students. This linkage between prior and recently incorporated knowledge, can avoid as much as possible mechanistic learning. Discovery learning promotes and provides a democratizing element to the educational fact.

In this work we put the look on several characteristics that influence upon the reluctance/acceptance to bridge basic and applied contents. Those were: age, genre, career, reading habits, invoked professional objectives, and abilities to search information and also to recognize scenarios for preventive actions and to propose measures that should be based in the contents of basic sciences.

Those characteristics that are more associated with a greater success rate in establishing cognitive connection as expressed in changes toward basic science knowledge are linked to individual abilities that have been developed at school and in the home environment reading, argumentation and discussion and capacity to search information to a level of increased difficulty (Wilkerson \& Gijselaers, 1996; Dinther et al., 2011; Hickey et al., 2012; Hubbard, 2015).

Ability to understand and express different and even controversial ideas is a common feature in those students that fulfill the significant learning requirements. Ability to identify what is really scientific and what isn't is essential, but also requires a good deal of basic knowledge to be developed.

This approach considers the logics and concepts that support the student research team's assumptions and developments. This procedure is an attempt to solve the cognitive dissonance between how teachers represent information to the students and how they processes that information through and strategy that place the student in both places, those in which is a receptor of information and those in which is a source.

A modeled situation that can be related to experiences as illnesses, epidemics, a book or films are more likely to be retained as the knowledge that is linked to those processes underlying the facts. Moreover, the analysis of the further implications of certain lines of action can function as trigger for the anchorage of that basic knowledge; for instance the biochemistry of chromium DNA damage or the agents that increases permeability in the enteric epithelium in celiac disease.

There is a condition that improves that focus: The ability to transmit a motivating and compromising attitude toward deep learning is altogether with the generation of an environment where the student feel that is emotion- 
ally supported. Teaching must be complemented by research, because that is linked with reality as is connected the professional activity itself. A physician, a dentist, nurse or nutritionist are in position to give a real perspective of what they are trying to teach, but if they are also researchers, the relationship between the basic and the "real life" springs up without any difficulty. Universities must be enriched regularly, with the contributions of research conducted on campuses (Iwaoka et al., 2010).

The ability to choose the appropriate decision springs from the knowledge and skills of those students that must be considered as decision makers that are under development. This future professional must find support in knowledge and ethics. Ethics that is intended to promote well-being for most people, should act in this educative context as a connector with meaningful learning.

This problematic situation should act as an inception of an artificially constructed dichotomy that through the exposition of what could happen if the future professional and decision maker don't know how to act properly when facing a health threatening event in the real word. That should be strong enough to serve as a memory for the subsumption process proposed by Ausubel, in which new material is related to relevant ideas in the existing cognitive (and ethical, this statement is mine) structure in the students and helps them to achieve a meaningful learning (Ausubel, 1962).

This is the moment when the informed beneficence concept plays a roll. Most of students react with a reinforcement of their sense of responsibility when the exercise set them in front of the consequence of an incorrect solution to a particular problem of a particular people. On this respect, we agree with Hafferty and Franks, 1994 statement that ... "medical (and other professions as Nursing), the comment is mine. Training involves considerably more than the acquisition of a new knowledge base, it also involves learning new rules about feelings and about mistakes and the management of failures".

Management of mistakes and failures could be a part of a self protective strategy learned and elaborated by professionals that without solid ethical grounds can develop into a justification for malpractice. Our view is that all efforts did by students along their careers, in order to acquire basic and applied knowledge and skills, can guarantee a good practice, with non maleficence and beneficence as a guide for action.

The core of the concept of informed beneficence is related to the assumption that the expectation of good results in therapeutic interventions could increases as the information and knowledge of the professional does. It isn't by no means a naif concept that ignores the huge amount of variables influencing a therapeutic outcome, but stresses the ethical value of the learning process as a way to prepare ourselves to do good.

We must emphasize that there's no guilt issue about "education to elucidate and help", this view provides a reason to learn and understand those concepts that lay behind the ability to solve problems in favor of public. In this approach, not only the cognitive side is relevant, but also the axiological one.

\section{Acknowledgements}

I would like to thank Mrs. Vanesa Miana for her helpful cooperation, to Dr. Rodny Britos for being highly cooperative and to Professor Susana Segovia for her careful reading and criticisms.

\section{References}

Acosta, S. F., \& García, M. C. (2012). Estrategias de enseñanza utilizadas por los docentes de biología en las universidades públicas. Omnia, 18, 67-82.

Adams, D. (2011). Effective Learning in the Life Sciences: How Students Can Achieve Their Full Potential (pp. 25-40). Oxford: John Wiley \& Sons. http://dx.doi.org/10.1002/9781119976646

American Association for the Advancement of Science (2011). Vision and Change in Undergraduate Biology Education: A Call to Action. Washington DC: American Association for the Advancement of Science.

Armstrong, J. S. (2012). Natural Learning in Higher Education. In N. M. Seel (Ed.), Encyclopedia of the Sciences of Learning 1 (pp. 5-10). Heidelberg: Springer.

Ausubel, D. P. (1960). The Use of Advance Organizers in the Learning and Retention of Meaningful Verbal Material. Journal of Educational Psychology, 51, 267-272. http://dx.doi.org/10.1037/h0046669

Ausubel, D. P. (1962). A Subsumption Theory of Meaningful Verbal Learning and Retention. The Journal of General Psychology, 66, 213-224. http://dx.doi.org/10.1080/00221309.1962.9711837

Azizi-Fini, I., Hajibagheri, A., \& Adib-Hajbaghery, M. (2015). Critical Thinking Skills in Nursing Students: A Comparison between Freshmen and Senior Students. Nursing and Midwifery Studies, 4, Article ID: e25721. 
http://dx.doi.org/10.17795/nmsjournal25721

Balanay, C. A. S., \& Roa, E. C. (2013). Assessment on Students' Science Process Skills: A Student-Centred Approach. International Journal of Biology Education, 3, 25-39.

Bjorg, D., Leland, A., \& Dale, J. G. (2013). What Factors Facilitate Good Learning Experiences in Clinical Studies in Nursing: Bachelor Students' Perception. ISRN Nursing, 20, 1-7.

Bruner, J. (1960). The Process of Education. Cambridge, MA: Harvard University Press. (Twenty-Fifth Printing, 1999)

Burnard, P. (1999). Carl Rogers and Postmodernism: Challenged in Nursing and Health Sciences. Nursing and Health Sciences, 1, 241-247. http://dx.doi.org/10.1046/j.1442-2018.1999.00031.x

Ceballos, N. (2007). Natural and Exacts Sciences Careers: Is there a Shortage of Students? Qviva, 6, 1-3.

Chamany, K., Allen, D., \& Tanner, K. (2008). Making Biology Learning Relevant to Students: Integrating People, History, and Context into College Biology Teaching. CBE-Life Sciences Education, 7, 267-278. http://dx.doi.org/10.1187/cbe.08-06-0029

Clarke, A. J. (2014). Managing the Ethical Challenges of Next-Generation Sequencing in Genomic Medicine. British Medical Bulletin, 111, 17-30. http://dx.doi.org/10.1093/bmb/ldu017

DeHaan, R. L. (2009). Teaching Creativity and Inventive Problem Solving. CBE-Life Sciences Education, 8, 172-181.

Dinther, M. D., Dochy, F., \& Segers, M. (2011). Factors Affecting Students' Self-Efficacy in Higher Education. Educational Research Review, 6, 95-108. http://dx.doi.org/10.1016/j.edurev.2010.10.003

Domínguez Gutiérrez, S. (2013). What Students Think about Professional Careers? Revista de Estudios para el Desarrollo Social de la Comunicación, 7, 163-187.

Enríquez Clavero, J. O., Mendoza Faget, T., \& Carbó Ayala, J. E. (2009). Approach to Teaching Problem as a Viable Alternative Methodology in Higher Medical Education. EDUMECENTRO, 1, 27-30.

Fasser, C., McGuire, A., Erdman, K., Nadalo, D., Scott, S., \& Waters, V. (2007). The Ethics Workup: A Case-Based Approach to Ethical Decision-Making Instruction. The Journal of Physician Assistant Education, 18, 34-41. http://dx.doi.org/10.1097/01367895-200718010-00006

Felder, R. M., \& Brent, R. (2009). Active Learning: An Introduction. ASQ Higher Education Brief, 2, 4-9.

Feudmer, C., \& Christakis, D. A. (1994). Making the Rounds: The Ethical Development of Medical Students in the Context of Clinical Rotations. The Hastings Center Report, 24, 6-12. http://dx.doi.org/10.2307/3562379

Fortus, D., Krajcik, J., Dershimer, R. C., Marx, R. W., \& Mamlok-Naaman, R. (2005). Design-Based Science and RealWorld Problem-Solving. International Journal of Science Education, 27, 855-879.

http://dx.doi.org/10.1080/09500690500038165

Giere, R. N. (1999). Using Models to Represent Reality. In L. Magnani, N. J. Nersessian, \& P. Thagard (Eds.), Model-Based Reasoning in Scientific Discovery (pp. 41-57). New York: Kluwer Academic/Plenum Press. http://dx.doi.org/10.1007/978-1-4615-4813-3 3

Gilbert, J. K., \& Boulter, C. J. (1998). Learning Science through Models and Modelling. In B. J. Fraser, \& K. G. Tobin (Eds.), International Handbook of Science Education (pp. 53-56). London: Kluwer Academic.

Guanche Martínez, A. (2005). Problem Based Learning in Natural Sciences. http://www.rieoei.org/did mat30.htm

Hackett, G., Brown, S. D., \& Lent, R. W. (1994). Toward a Unifying Social Cognitive Theory of Career and Academic Interest, Choice, and Performance. Journal of Vocational Behavior, 45, 79-122. http://dx.doi.org/10.1006/jvbe.1994.1027

Hafferty, F., \& Franks, R. (1994). The Hidden Curriculum, Ethics Teaching, and the Structure of Medical Education. Academic Medicine, 69, 861-871.

Hickey, N., Harrison, L., \& Sumsion, J. (2012).Using a Socioecological Framework to Understand the Career Choices of Single- and Double-Degree Nursing Students and Double-Degree Graduates. ISRN Nursing, 2012, Article ID: 748238. http://dx.doi.org/10.5402/2012/748238

Hubbard, J. (2015). Predicting Student Nurse Success: A Behavioural Science Approach. Nurse Education Today, 35 , e1-e3. http://dx.doi.org/10.1016/j.nedt.2015.02.017

Hyerle, D. (2008). Visual Tools for Transforming Information into Knowledge. Chap. 2. Facilitating the Network Brain and the Patterning Mind (2nd ed.). Thousand Oaks, CA: Corwin Press.

Iwaoka, W. T, Li, Y., \&Rhee, W. Y. (2010). Research in Food Science Education: Measuring Gains in Critical Thinking in Food Science and Human Nutrition Courses: The Cornell Critical Thinking Test, Problem-Based Learning Activities, and Student Journal Entries. Journal of Food Science Education, 9, 68-75. http://dx.doi.org/10.1111/j.1541-4329.2010.00100.x

Keijsers, C. J. P. W., Custers, E. J. F. M., \& Ten Cate, O. T. J. (2009). A New, Problem Oriented Medicine Curriculum in Utrecht: Less Basic Science Knowledge. Nederlands Tijdschrift voor Geneeskunde, 153, 1654-1659. 
Kember, D. (2009). Promoting Student-Centered Forms of Learning across an Entire University. Higher Education, 58, 1-13. http://dx.doi.org/10.1007/s10734-008-9177-6

Kilroy, D. A. (2004). Problem Based Learning. Emergency Medicine Journal, 21, 411-413. http://dx.doi.org/10.1136/emj.2003.012435

Kosgeroglu, N. (2009). An Investigation on Nursing, Midwifery and Health Care Students Learning Motivation in Turkey. Nurse Education in Practice, 9, 331-339. http://dx.doi.org/10.1016/j.nepr.2008.07.003

Labov, J. B., \& Huddleston, N. F. (2008). Integrating Policy and Decision Making into Undergraduate Science Education. CBE: Life Sciences Education, 7, 347-352. http://dx.doi.org/10.1187/cbe.08-09-0056

Lazic, E., Dujmovic, J., \& Hren, D. (2006). Retention of Basic Science Knowledge at Clinical Years of Medical Curriculum. Croatian Medical Journal, 47, 882-887.

Magnani, L., \&Nersessian, N. J. (Eds.) (2002). Model-Based Reasoning. Scientific Discovery, Technological Innovation, Values. New York: Kluwer Academic/Plenum Publishers.

McLellan, H. (Ed.) (1996). Situated Learning Perspectives. Englewood Cliffs, NJ: Educational Technology Publications.

Muller, D., \& Kase, N. (2010). Challenging Traditional Premedical Requirements as Predictors of Success in Medical School: The Mount Sinai School of Medicine Humanities and Medicine Program. Academic Medicine, 85, 1378-1383.

http://dx.doi.org/10.1097/ACM.0b013e3181dbf22a

Norman, G. (2000). The Essential Role of Basic Science in Medical Education: The Perspective from Psychology. Clinical \& Investigative Medicine, 23, 47-51.

Norman, G., \& Schmidt, H. G. (2000). Effectiveness of Problem Based Learning Curricula: Theory, Practice and Paper Darts. Medical Education, 34, 721-728. http://dx.doi.org/10.1046/j.1365-2923.2000.00749.x

Pangaro, L. (2010). The Role and Value of the Basic Sciences in Medical Education: The Perspective of Clinical Education-Students' Progress from Understanding to Action. Medical Science Educator, 20, 307-313.

Pellegrino, E. D. (1993). The Metamorphosis of Medical Ethics: A 30 Years Retrospective. JAMA, 269, 1158-1162. http://dx.doi.org/10.1001/jama.1993.03500090094039

Potter, V. R. (1988). Global Bioethics: Building on the Leopold Legacy. East Lansing, MI: Michigan State University Press.

Resnick, L. B. (2009). Nested Learning Systems for the Thinking Curriculum. Educational Researcher, 39, 183-197. http://dx.doi.org/10.3102/0013189X10364671

Rodríguez, L. M., Marín, C., Moreno, S. M., \&Rubano, M. C. (2007). Paulo Freire: Pedagogy from Latin America. Science, Teaching and Technology, 17, 129-171.

Rognstad, M. K., \& Aasland, O. (2007). Change in Career Aspiration and Job Values from Study Time to Working Life. Journal of Nursing Management, 15, 424-432. http://dx.doi.org/10.1111/j.1365-2834.2007.00655.x

Rowe, M. P., Gillespie, B. M., Harris, K. H., Koether, S. D., Shannon, L. J. Y., \& Rose, L. A. (2015). Redesigning a General Education Science Course to Promote Critical Thinking. CBE: Life Sciences Education, 14, 1-12. http://dx.doi.org/10.1187/cbe.15-02-0032

Schwarz, C. V., Reiser, B. J., Davis, E. A., Kenyon, L., Acher, A., Fortus, D., Shwartz, Y., Hug, B., \& Krajcik, J. (2009). Developing a Learning Progression for Scientific Modeling: Making Scientific Modeling Accessible and Meaningful for Learners. Journal of Research in Science Teaching, 46, 632-654. http://dx.doi.org/10.1002/tea.20311

Spencer, A. L., Brosenitsch, T., Levine, A. S., \& Kanter, S. L. (2008). Back to the Basic Sciences: An Innovative Approach to Teaching Senior Medical Students How Best to Integrate Basic Science and Clinical Medicine. Academic Medicine, 83, 662-669. http://dx.doi.org/10.1097/ACM.0b013e318178356b

Tarhan, L., \& Ayyıldız, Y. (2015). The Views of Undergraduates about Problem-Based Learning Applications in a Biochemistry Course. Journal of Biological Education, 49, 116-126. http://dx.doi.org/10.1080/00219266.2014.888364

Tysinger, J. W., Klonis, L. K., Sadler, J. Z., \& Wagner, J. M. (1997). Teaching Ethics Using Small-Group, Problem-Based Learning. Journal of Medical Ethics, 23, 315-318. http://dx.doi.org/10.1136/jme.23.5.315

Veatch, R. M., Haddad, A. M., \& English, D. C. (2009). Case Studies in Biomedical Ethics: Decision-Making, Principles, and Cases. Oxford: Oxford University Press.

Weyrich, L. S., \& Harvill, E. T. (2013). Teaching Ethical Aptitude to Graduate Student Researchers. Accountability in Research: Policies and Quality Assurance, 20, 5-12. http://dx.doi.org/10.1080/08989621.2013.749742

Wilkerson, L., \& Gijselaers, W. H. (1996). Concluding Comments. In L. Wilkerson, \& W. H. Gijselaers (Eds.), Bringing Problem-Based Learning to Higher Education: Theory and Practice (pp. 101-104). San Francisco, CA: Jossey-Bass.

Wood, D. F. (2003). Problem Based Learning. BMJ, 326, 328-330. http://dx.doi.org/10.1136/bmj.326.7384.328

Yasushi, K., Sachiko, H., Emiko,Y., Masashi, T., Akizumi, T., Akitaka, S. H., \& Yoshiharu, A. (2013). Five Reasons for the Lack of Nursing Students' Motivation to Learn Public Health. The Tohoku Journal of Experimental Medicine, 231, 179186. 